\title{
Studying the Justice from Management Perspective
}

\author{
Dr.Ali Nasr Esfahani ${ }^{1}$ \\ Assistant Professor, Department of Management, Faculty of Administrative sciences and \\ Economics, University of Isfahan, Isfahan, Iran

\section{Mohammad Hossein Forghani} \\ M.A. Student, Department of Management, Faculty of Administrative Sciences and Economics, \\ University of Isfahan, Isfahan, Iran

\section{Mohamad Ghafari} \\ Ph.D. Candidate of Marketing, Department of Management, Faculty Administrative sciences \\ and Economics, University of Isfahan, Isfahan, Iran \\ DOI: 10.6007/IJARBSS/v3-i7/30 URL: http://dx.doi.org/10.6007/IJARBSS/v3-i7/30

\begin{abstract}
Justice isn't new concept, but it considered and attended during past times. This is one of the most important concerns of human being from past to now is implementation and realization of justice. Also justice is one of the most important issues that its realization leads to development and improvement of societies. Therefore the main purpose of this study is to investigate justice from management scientist's perspective and then social and organizational justice and their different types have been examined.
\end{abstract}

Keywords: Justice, Social Justice, Organizational Justice

\section{Introduction}

Justice in nowadays meaning and perception has close relationship with some concepts such as freedom, friendship, and equation. Indeed, many systems and entities judged based on this fact whether all of their members have equal rights and these systems and entities satisfy needs and wants of their members. In we want to offer a more comprehensive definition from justice, it could define as "when social norms system is justice that everybody live based on humanity mettle" (Golparvar, 2006: 12). Observation of justice principle and equation and also prevention from cruelty and injustice are the most important principals that are source of penetration in other's consciences and finally lead to effectiveness of manager. Though observation of justice is an innate issue that is desirable and honorable for everybody, but injustice, oppression, and cruelty are innate. There isn't anybody that advertises oppression

\footnotetext{
${ }^{1}$ Corresponding author: Assistant Professor, Department of Management, Faculty of Administrative sciences and Economics, University of Isfahan, Isfahan, Iran, email: alin@ ase.ui.ac.ir
} 
and disavows justice; even the most oppression peoples do their action in justice frame through any justification (Amiri, 2008: 164).

Justice needs much capability and competency, if justice culture developed comprehensively and people perceive justice in their life, then they characterize justice as their critical resuscitative factors and seek to maintain it. Also responsible individuals should start justice by themselves and then reinforce justice spirit and culture in societies employees and employers and finally in peoples (Mansorilarijani, 1990: 78).

\section{Justice}

Justice has different and diversified definitions that could discuss and think in political, religious, social, and other districts. Some of these definitions indicated in following section.

Justice is making just, Jourjani indicated that justice is resisting in vocabulary and it includes resistance on right path and prevention from which is scruple in religious (Rezaeian, 2005: 37). Justice is including everything in its place and this place specified based on rights and truth (Amiri, 2008: 169).

Rawls in his book "theory of justice" indicated that the purpose of thought is to achieving truth and the purpose of social entities is to achieving justice. Justice is which framework that different individuals have opportunity to achieve their goals. He considers efficiency as justice. His opinion is creating actual justice among conflicting demands of humans (Zamanrostami, 2005: 118).

\section{Social justice}

Every society, that seeks to achieve health, felicity, and welfare of its members, should act based on justice (Mnasourilarijani, 2010: 76). Social justice interprets and applied in which society that this society is able to create desirable background to realize friendship and peaceful that its members achieve their life, security, and hygiene needs and achieve their rights (Mousavi, 2001: 177-178).

Also it should remember in definition of social justice that social entities and phenomenon, which are related to each other, should act in their position to maintain overall order and coordination (Mansourilarijani, 2010: 68). Social justice is to behave appropriately with each other (Mousavi, 2001: 178).

\section{Organizational justice}

Justice is an abstract concept that different interpretations derive from it. When concept of justice discussed in organizational environment, organizational justice is used. Greenberg believed that perception of organizational justice is necessary to effectiveness of organizational performance and satisfaction of organizational members (Aminrkhani et al., 2008: 21-22). Organizational justice is a concept that used to describe the role of justice that has direct relationship with occupation positions. Especially it is discussed in organizational justice which methods used to behave employees so that sense that they behaved equally (Naami and Shekarshekan, 2006: 80). In the management literature, organizational justice concept is 
introduced by Greenberg for the first time in 1987. Based on Greenberg, organizational justice is related to employee's perception from occupational equality in organization. He used this concept to describe and interpret role of equality in occupational environment. In typology of organizational justice, three concepts of justice including procedural, interaction, and distributive justices introduced (Sayyedjavadin et al., 2008: 55).

\section{Types of organizational justice}

Three types of organizational justice identified in organizational environments by authors and researchers that each of them described in following section.

\section{Distributive justice}

Distributive justice refers to individual's perception from justice observation in distribution and allocation of resources and premiums. In other words, this refers to extend that individuals relate premiums to their performance (Rezaeian, 2005: 43). Based on Adams, when equation achieved that employee's percept ratio of their inputs (efforts) to their outputs (premiums) is equal with ratios of their colleagues (Ivancevich and Matteson, 1996, 17). Generally employees evaluate equality of results with respect to a reference standard that isn't based on a similar base. Because of this fact, allocations could judge in front of results of allocation especial rules. Especially the following three rules attended in distributive justice:

- Equality: every member of social group receive equal result

- Need: the most needful individual should receive the most compensation

- Justice and equality: equally compensation should is based on ratio or inputs of everybody

\section{Procedural justice}

Procedural justice refers to perceived justice from process that used to determine premiums distributions (Yaaghoubi et al., 2009: 26). Based on the theory of procedural justice, if people perceive justice in ongoing procedures of decision making in term of income distribution then have more motivation to better performance; because they know that in such conditions their performance evaluated precisely, but is they think that responsible haven't awareness from their services then their performance doesn't evaluated precisely or responsible judge their performance based on their individual opinions then they haven't much motivation. Theory of procedural justice seeks to find reasons of equality or inequality of procedures (Rezaeian, 2005: 49). Increasing perception of procedural justice leads that employees oversee their supervisor and organization with positive vision; even they don't satisfy from salary, promotions, and other individual outcomes (Robbins, 2001: 171). The results of different studies indicate that people perceive which procedures equally those are consistence with following six rules: (Rezaeian, 2005: 49-50)

1. Don't conflict with each other

2. Don't influenced by prejudice 
3. Are precise

4. Are correctable

5. Indicate to opinions of stakeholders

6. And are based on moral standards

\section{Interactive justice}

Addition to procedural and distributive justices, there third type of justice that indicates quality of interpersonal behaviors is the most important factor of justice perception during confirmation of organizational processes and distribution of organizational results (Bies and Shapiro, 1987: 210). Interactive justice defined based on perceived equality from interpersonal communications in term of organizational procedures and quality of interpersonal communications. This type of organizational justice considers equality of decision maker's behavior in process of organizational decision making. Procedural justice concentrates on supervisor's behaviors and their role in organizational justice observation and conceptually is similar to informal behavior quality; while procedural justice conceptually is similar to formal decision making (Sayyedjavadin et al., 2008: 57).

\section{Importance of justice}

Justice is one of the important visions of human beings and it attended by peoples in every era (Bayat, 2001: 12). Justice is one of the important challenges of scientists and philosophers and considered as the most important needs of societies during past times. Khaje Nasir considered justice as excellent prepayment. He also considered equality and proportion in justice and believed that justice is the best path of pass to god (Gheysari, 2002: 118). Justice observation is one of the important effective factors on employee's satisfaction in organizations so that employee's perception of injustice in organization leads to their job dissatisfaction and this dissatisfaction influence their job performance. These perceptions influence customer's satisfaction especially in services organizations that employees have direct relationship with customers. Therefore perceptions of organizational justice leads to maintain customers that provides long-term maintaining and profitability (Zynalisomee, 2004: 1). Additionally organizational justice has some other results such as increasing motivation and employee's commitment toward work and organization.

In national level, if national income distributed in more justice manner then demand for internal products increase, investment increase in country, and finally economic growth achieved through social justice. Equally distribution of assets leads to increase total demand and this leads to increase production. Also equally distribution leads to increase efficiency of labor (because of having hygiene, proper food, and education) and this leads to increase production and economic growth (Gheysari, 2002: 109). Also Fayol consider justice in his 14 principles of management in term of improvement of organizations management and doing management function and indicated that "if organizations employees behaved equally and squarely, they seek to achieve organizational goals and are loyal toward organization" (Rezaeian, 2007: 46). 


\section{Outcomes of justice and injustice}

Justice in subordinates is one of the characteristics that can complement commitment and trusteeship of manager. Management zone is set that equality and justice should govern in here. Therefore the outcomes of justice and injustice indicated in following section. With respect to this fact that justice has positive outcomes in organizational environments, its opposite injustice has many effects on organizations if occur, such as:

1. Increasing probability of injustice expectations in organizational members

2. Increasing probability of multiple types of perceived injustice

3. Increasing continuousness of inactive behaviors among organizational members such as increasing absence, boredom, and change resistance

4. Creating new inactive culture (such as absence culture) (Rezaeian, 2005: 67).

Additionally studies indicate that organizational commitment and absence decrease and organizational performance decrease in which organizations that employees believe decision making process is injustice (Sayyedjavadin, 2008: 57). Therefore organizational justice show management and manager's attention to employees and creates Reliability Bridge that finally increases and reinforces employee's commitment to organization. In addition, organizational justice leads to perception of organizations legitimation (Baharifar et al., 2010: 112-113).

\section{Conclusion}

This study seeks to investigate justice from management scientist's perspective. As discussed in later sections, justice isn't new concept, but it considered and attended during past times. This is one of the most important concerns of human being from past to now is implementation and realization of justice. Also justice is one of the most important issues that its realization leads to development and improvement of societies. Justice in nowadays meaning and perception has close relationship with some concepts such as freedom, friendship, and equation. Justice needs much capability and competency, if justice culture developed comprehensively and people perceive justice in their life, then they characterize justice as their critical resuscitative factors and seek to maintain it. Justice has different and diversified definitions that could discuss and think in political, religious, social, and other districts. Justice is an abstract concept that different interpretations derive from it. When concept of justice discussed in organizational environment, organizational justice is used. Greenberg believed that perception of organizational justice is necessary to effectiveness of organizational performance and satisfaction of organizational members. Three types of organizational justice identified in organizational environments by authors and researchers that include procedural, interactive, and distributive justices. Procedural justice refers to perceived justice from process that used to determine premiums distributions. Distributive justice refers to individual's perception from justice observation in distribution and allocation of resources and premiums. Addition to procedural and distributive justices, there third type of justice that indicates quality of interpersonal behaviors is the most important factor of justice perception during confirmation of organizational processes and distribution of organizational results. Justice is one of the important visions of human beings and it attended by peoples in every era. Justice is one of the 
important challenges of scientists and philosophers and considered as the most important needs of societies during past times.

\section{References}

Amirkhani, Tayyebeh, Pourezat, Aliasghar, (2008), Indecision on Possibility of Social Capital Development though Organizational Justice in Public Organizations, Journal of Public Management, Vol. 1, pp 19-32.

Amiri, Alinaghi, (2008), Islamic Management, Tehran: Fajrevelayat publishers.

Baharifar, Ali, Javaherikamel, Mahdi, (2010), The Examination of Outcomes of Organizations Moral Values (through study of organizational justice, organizational commitment, and organizational citizenship behavior), Monthly of hyman development of police, Vol. 28, pp 95118.

Bayat, Asadallah, (2001), Justice Measure, Tehran: Masei publishers.

Bies, R.J.and Shapiro,d.I. (1987), "Interaction fairness judgments: the influence of causal accounts, Social Justice Research, No 1, 199-218.

Gheysari, Rajabali, (2002), The Study of Justice Importance in Economic Development from Islam Perspective, Journal of economic researches, Vol 5, 6, pp 105-127.

Goulparvar, Mohsen, (2006), Organizational Justice Post-motivations in Employees and Managers of Industries and Organizations of Isfahan City, Journal of human sciences, vol. 65, pp 11-34.

Matteson,M.T.(1996). Organizational Behavior and Management, Ivancevich, J. M McGrow-Hill Companies.Inc.

Mansourilarijani, Ismaeil, (1990), Islamic Management, Tehran.

Mousavi, Jamaladdin, (2001), Social Justice in Islam, Tehran.

Naamai, Abdazzahra, Shekrshekan, Hoseyn, (2006), The Investigation of Simple and Multiple Relationship between Organizational Justice and Organizational Civil Behavior among Employees of an Industrial Organization in Ahvaz City, Journal of psychology and educational sciences of Shahid Chamran University of Ahvaz, Vol. 1, pp 79-92.

Norozi, Hoseyn, (2002), The station of Justice and Advice in Governance of Ali, AM Thesis, Faculty of Islamic sciences, Qom university.

Robbins, S.P(2001). Organizational Behavior,New Dehli. Prentice Hall, Inc. 
Rezaeian, Ali, (2007), Fundamentals of Organization and Management, Tehran: SAMT publishers.

Rezaeian, Ali, (2005), Justice Expectation and Justice in Organization (Advanced Organizational Behavior Management), Tehran: SAMT publishers.

Sayyedjavadin, Sayyedreza, Farahi, Mohamadmahdi, and Taheriattar, Ghazaleh, (2008), the Recognition of Methods of Dimensions of Organizational Justice Effects on Different Aspects of Organizational and Job Satisfaction, Journal of Commercial Management, Vol. 1, pp 55-70.

Yaaghoubi, Maryam and et al., (2009), The Relationship between Organizational Justice with Job Satisfaction and Organizational Commitment among Employees of Selective Hospitals of Isfahan University of Medical Sciences, Journal of Health Management, Vol. 35, pp 25-32.

Zeynalisomee, Parvaneh, (2004), The Examination of Justice Observation Effects on Effectiveness of Services Organizations to Satisfy Customers, MA Thesis, faculty of human sciences, Tarbiat Modarres University. 